\title{
Microparticles of Herbal Extracts with Antioxidant Activity
}

\author{
Zulham $^{1,4}$, Gofarana Wilar ${ }^{2}$, Yasmiwar Susilawati ${ }^{3}$, Anas Subarnas ${ }^{2}$, Anis Yohana Chaerunisaa ${ }^{1, *}$
}

Zulham ${ }^{1,4}$, Gofarana Wilar ${ }^{2}$, Yasmiwar Susilawati ${ }^{3}$, Anas Subarnas ${ }^{2}$, Anis Yohana Chaerunisaa ${ }^{1, *}$

'Department of Pharmaceutics and Pharmaceutical Technology, Faculty of Pharmacy, Padjadjaran University, INDONESIA.

2Department of Pharmacology and Clinical Pharmacy, Faculty of Pharmacy, Padjadjaran University, INDONESIA.

${ }^{3}$ Department of Biological Pharmacy,

Faculty of Pharmacy, Padjadjaran University, INDONESIA.

${ }^{4}$ Sekolah Tinggi Ilmu Farmasi Makassar, INDONESIA.

\section{Correspondence}

\section{Anis Yohana Chaerunisaa}

Department of Pharmaceutics and Pharmaceutical Technology, Faculty of Pharmacy, Padjadjaran University، INDONESIA.

E-mail: anis.yohana.chaerunisaa@unpad.ac.id

\section{History}

- Submission Date: 17-09-2020;

- Review completed: 08-10-2020;

- Accepted Date: 22-10-2020.

DOI : 10.5530/pj.2021.13.38

Article Available online

http://www.phcogj.com/v13/i1

\section{Copyright}

(C) 2021 Phcogi.Com. This is an openaccess article distributed under the terms of the Creative Commons Attribution 4.0 International license.

\begin{abstract}
Plants that have antioxidant content have been shown to have efficacy on the body, antioxidants have several drawbacks including being sensitive to environmental factors such as light, heat, $\mathrm{pH}$, and oxygen. Microencapsulation is a method that has several advantages including providing several benefits, namely microparticles formulated to protect the core from the environment, cover up discomfort, maintain volatility or cell survival, separate incompatible substances, protect the body from side effects, and optimize, extend, or target drug effects. The choice of the type of polymer used will determine the characteristics of the microparticles produced, therefore a suitable coating material is needed to produce the microparticles. This review article was made to find out the results of research conducted in the manufacture of microparticles by using polymers which are expected to be useful to provide information on the basis of the selection of polymers and methods of making microparticles produced to maintain the stability of substances that are efficacious as antioxidants. Based on the results of the literature search, microencapsulation is a method used to maintain the stability of antioxidant content that has a therapeutic effect.
\end{abstract}

Key words: Microparticle, Extract, Antioxidant, Polymer.

\section{INTRODUCTION}

Antioxidants have health benefits such as reduces the occurrence of different disorders like: aging, cancer, anti-inflammatory role related to chronic diseases, like obesity and diabetes, liver disease, cardiovascular disease, cataract, nephrotoxicity, neurodegenerative disorders, antibacterial, antiallergic, anti-hypertensive, antiviral and skin wound healing effects have been attributed to the role of antioxidants. ${ }^{1,2}$

Due to their antioxidant properties, several health benefits related to their consumption are reported in the literature. The relevant antioxidant activities of bioactive substances may be hampered due to their degradation triggered by light, oxygen, temperature, moisture, solvent, other environmental conditions and existence of unsaturated bonds in the molecular structures. The instability of antioxidant compounds is associated with different processing and storage conditions. These facts have led researchers to investigate new forms of processing that provide minimal degradation. It is therefore envisaged that microencapsulation could preserve the stability of this kind of natural substance, besides allowing their controlled release during the shelf life of the product of interest. Microencapsulation is a promising possibility to stabilize extracts and allow their addition to products in a more stable form. ${ }^{2-4}$

The antioxidant characteristics enable their use in food, cosmetics and pharmaceuticals, either to increase the shelf life of these products, reducing the amount of synthetic antioxidants in their composition, or to promote beneficial effects to the human body. However, as antioxidants compounds are unstable, the application of these bioactive compounds to new products is very restricted. ${ }^{4}$

The application of microencapsulated bioactive compounds as functional applications exhibits significant potential. The ingredients mostly enveloped in a coating material, thereby conferring useful or eliminating useless properties from the original ingredient. ${ }^{5}$ The substance that is encapsulated may be called the active agent or core ingredient, while the substances that provide the protection are called the coating or shell materials. The coating material of encapsulates used in food products should be food grade and able to form a barrier protecting the active agent from adverse effects of moisture, heat, light, oxygen, and other reactive components present in the matrix.

Microencapsulation is a process of packaging solids, liquids, or gaseous materials as active material with a continuous film as a coating to form capsules, whereby the functional ingredients are protected from their environment by entrapping them within a protective coating material and forming particles with diameters of a few nanometers to a few millimeters. ${ }^{6,2}$ Thus, microencapsulation with an appropriate carrier is an alternative technology for enhancing the storage and enviromental stability of bioactives as well as giving an advance to mask offflavour.

A number of coating or matrix materials can be selected depending upon desired properties of the final microcapsule including stability and unaltered bioavailability, as well as compatibility with selected microencapsulation techniques and high encapsulation efficiency. Among them, proteins, sugars, starches, gums, lipids, and cellulose derivatives are most popular, as covered elsewhere 
in this book. Ideal coating materials should have a bland, neutral taste and odor, good film-forming properties, low viscosity when present in solutions or suspensions, and desirable gelling and barrier properti. As a coating or encapsulating system is designed to protect the core material from environmental factors that may cause its deterioration and to prevent premature interaction between the core material with other food components, it is of paramount importance when selecting the coating material that it be stable under processing and storage conditions. $^{6}$

The purpose of this review is to provide an evaluation based on the selection of various types of polymers and the method of making microparticle extracts that have antioxidant properties. To achieve this goal, research that explains the results of selecting polymers used in the manufacture of micro particles includes the effect of encapsulation on antioxidant capacity, stability, solubility and content of bioactive compounds.

\section{Current research on microencapsulation of extracts}

The encapsulation technique is considered a promising protection method which involves packaging smaller core materials in the wall matrix. Encapsulation technology is defined as a technique in which a substance in a solid, liquid, or gas state (encapsulation agent or active core) is packed with encapsulation material (wall or shell material). Encapsulation agents can be engineered to release active ingredients gradually through specific triggers (such as fractures due to heat, solvation, diffusion, and pressure), and can be engineered to be opened in specific areas of the body. Capsules are vesicles or small particles that can range from sub-microns to several millimeters. The size of the dispersed particles or powder formed can be classified as macro $(>5000$ $\mu \mathrm{m})$, micro $(1.0-5000 \mu \mathrm{m})$ or nano $(<1.0 \mu \mathrm{m})$. Many morphologies can be produced for encapsulation, but three main morphologies are more commonly used: mononuclear capsules, which have one core enveloped by a wall material, a polynuclear core, which has two or more nuclei covered by a wall material; and aggregates, which have many nuclei embedded in the matrix. ${ }^{3}$

Several parameters are used to verify the quality of encapsulation, and their characteristics depend on the encapsulation process used. Encapsulation efficiency is one of the most important quality parameters of the encapsulation technique because it determines the ability of the wall material to hold the core material inside the microcapsules. This parameter allows us to determine whether the encapsulation method and the wall material used are capable of coating the core material efficiently. Particle size is another quality parameter that must be observed and its reduction. The encapsulation method can improve the properties of delivery, solubility, and bioavailability because it produces a higher surface area per unit volume, increasing its biological activity. Small size, on a micro and nano scale, can provide long gastrointestinal retention times caused by increased bioadhesive properties in the mucus that covers the intestinal epithelium. Particles made with biopolymers can also use $\zeta$-Potential as a quality parameter. This parameter determines the surface properties by measuring the difference in effective electric potential generated by the surface charge density of the biopolymer used and depends on the $\mathrm{pH}$ of the medium. The $\zeta$-Potential measurement can be used to verify the stability of aggregation and to control the retention and release of bioactive molecules among other functions. ${ }^{3}$

In many reviews, microencapsulation has been used for protection, modification, and controlled delivery of many food ingredients, including acidulants, flavors, sweeteners, colorants, enzymes and microorganisms, antioxidants, leavening agents, and nutritional ingredients such as vitamins and minerals. ${ }^{6}$ Research on microencapsulation of extract which had been reported in many publications was summarized in Table 1.

\section{Polymers for microencapsulation}

Although various encapsulating agents can be used, both individually and in combination, some characteristics should be observed, such as their ability to form films, biodegradability, resistance to gastrointestinal tract, viscosity, solids content, hygroscopicity, and cost. An effective combination of appropriate coating materials and encapsulation techniques is the key for developing a microencapsulated system as it plays an important role in the physical and chemical properties of the resulting microparticles, such as particle size, porosity, density, flowability, integrity, reactivity/stability, and release properties. For each active ingredient the appropriate choices of process and wall materials depend greatly on the end use of the microencapsulated particles. ${ }^{6}$

Among various encapsulating agents, such as gum Arabic, lactose, maltodextrins, and xanthan gum, maltodextrins with degrees of dextrose equivalence (DE) between 10 and 20 are frequently used in the spraydrying process. These substances have several advantages, including the ability to contain the acidulants, such as adipic acid, ascorbic acid, citric acid, fumaric acid, and malic acid, protect the sensitive substances, reduce the hygroscopicity of the products, reduction of stickiness of the fruit extracts, and provide a high degree of flow and fast dissolution of the microparticles in water. ${ }^{16}$

Chitosan has been chosen as the microencapsulating agent because of its wide applicability as a biodegradable, biocompatible and non-toxic polymer. The fact that it is also a natural and low- cost polymer increase the interest in its use in encapsulation of a natural active substance. Chitosan microparticles are able to prolong the residence time of drugs applied topically thus improving the drug bioavailability. ${ }^{7}$

Gum Arabic (GA) is considered an encapsulating agent par excellence has reasonable emulsifying properties with acceptable protecting effects, but its viscosity at high concentrations limits its industrial applications and it is used mainly due to its high water solubility characteristics, low viscosity, and emulsifying properties. ${ }^{18}$ On the other hand, its high price has motivated the search for total or partial substitution of this encapsulant. Maltodextrin (MD) a hydrolysed starch, offers advantages as a microencapsulation material is the most commonly used material for this purpose, especially for encapsulating extracts and low-cost material with a neutral aroma and flavor, high water solubility and low viscosity at high solids content, being able to pro-vide effective protection against oxidation ; however, it has low emulsifying capacity and protective effects. ${ }^{18}$ Because a single wall material does not meet the requirement of high powder recovery with satisfactory quality characteristics, combining wall materials may be beneficial.

For this reason, it is necessary to subject them to processes like spraydrying to extend their shelf-life but without affecting their useful properties. To this end, carrier materials like maltodextrins, inulin and gums need to be added to the solutions to prevent stickiness and the loss of volatile compounds. Maltodextrin, derived from starch hydrolysis and made up of $\beta$-D-glucose chains, is one of the most commonlyused and studied carriers due to its high solubilization capacity, mild flavor, low cost and ability to reduce stickiness and improve product stability. Maltodextrin's properties are defined by the degree of starch degradation, indicated by the dextrose equivalent value (DE) which measures the content of reducing-end groups. Different DE values result in distinct properties due to modifications of this substance's physicochemical parameters. One way to evaluate these changes consists in determining the glass transition temperature (Tg), which decreases at higher DE values. A high maltodextrin Tg, for example, provides a stable glassy matrix at room temperature. ${ }^{38}$

Biopolymer microparticles can be used to encapsulate lipophilic bioactive agents, which can be manipulated to protect bioactive agents from degradation in products during storage or within the 
Table 1: Various manufacturing results of various microparticle extracts polymer.

\begin{tabular}{|c|c|c|c|c|c|}
\hline Polymer & Compound & Content & Method & Results & Reference \\
\hline Chitosan & $\begin{array}{c}\text { Plinia cauliflora } \\
\text { (jabuticaba) fruit } \\
\text { peel extract }\end{array}$ & Polyphenols & Spray drying & $\begin{array}{l}\text { - After } 60 \text { days }(97 \pm 9 \% \text { and } 83 \pm 4 \% \text {, respectively) and at a stress } \\
\text { temperature for } 30 \text { days }(74 \pm 19 \%) \text { it was verified that the } \\
\text { microparticles were better than the extract in maintaining the } \\
\text { total polyphenols at the three temperatures studied }(\mathrm{p}<0.05) \text {. } \\
\text { - The results showed the development of stable chitosan } \\
\text { microparticles encapsulating jabuticaba peel extract successfully } \\
\text { produced by spray drying. } \\
\text { - These microparticles were capable of protecting the total } \\
\text { polyphenols contained in the extract, promoting the stability of } \\
\text { these compounds during storage, which enhables their application } \\
\text { in food or cosmetic products. }\end{array}$ & (1) \\
\hline Chitosan & Aloe vera & a-tocopherol & Spray drying & $\begin{array}{l}\text { The particles were spherical, with a rough surface, micrometric } \\
(\mathrm{D}[4,3]=9.59 \mathrm{~mm}) \text {, unimodal and polydisperse (SPAN of } 1.12) \text {. } \\
\text { The final a-tocopherol acetate concentration in the powder was } \\
91 \% \text { of the expected amount. } \\
\text { - The microparticles were capable ofmaintaining the concentration } \\
\text { of a-tocopherol acetate for a longer time than a commercially } \\
\text { available pulverized form of a-tocopherol acetate. }\end{array}$ & 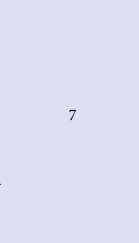 \\
\hline Chitosan & Rutin & Rutin & $\begin{array}{c}\text { Formulated by } \\
\text { a rotor-stator } \\
\text { homogenize at the } \\
\text { homogenization } \\
\text { speed } 10,000 \mathrm{rpm} \text {. }\end{array}$ & $\begin{array}{l}\text { The characterization of the prepared films showed that chitosan- } \\
\text { coated microparticles are well dispersed in the gelatin film. } \\
\text { The addition of microparticles into the gelatin film decreased } \\
\text { the elongation-at-break and water vapor permeability of the } \\
\text { biopolymer. } \\
\text { - The light barrier properties of edible films show that UV light is } \\
\text { absorbed with the addition of microparticles to the biopolymer } \\
\text { matrix. } \\
\text { - The FTIR absorption spectra for biocomposite films indicated } \\
\text { good protection of antioxidant rutin, which remains unaffected in } \\
\text { the presence of the higher permeability. } \\
\text { - These characterizations show that the incorporation of chitosan- } \\
\text { coated microparticles charged with antioxidant rutin into gelatin } \\
\text { films is an ideal option for the development of active packaging for } \\
\text { extending shelf life. }\end{array}$ & 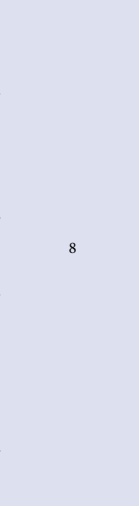 \\
\hline Alginat, Chitosan & $\begin{array}{c}\text { Pomegranate Peel } \\
\text { Extract }\end{array}$ & $\begin{array}{l}\text { Ellagitannins } \\
\text { (polyphenols) }\end{array}$ & Spray-drying & $\begin{array}{l}\text { Production yields were about } 40 \% \text { for alginate microparticles and } \\
41 \% \text { for chitosan. Mean diameters were } 2.45 \mu \mathrm{m} \text { and } 2.80 \mu \mathrm{m} \text {, and } \\
\text { encapsulation efficiencies were } 81.9 \% \text { and } 74.7 \% \text { for alginate and } \\
\text { chitosan microparticles, respectively. The spray-drying process } \\
\text { preserved the antifungal activity against Candida albicans. } \\
\text { - In this study, these agents did not differ in yield, size, efficiency } \\
\text { of encapsulation, or antifungal activity. The amount of the extract } \\
\text { in the microparticles was quantified by HPLC, and the process } \\
\text { of encapsulation preserved the antifungal activity of the extract } \\
\text { against C. albicans, which is responsible for mycosis in the buccal } \\
\text { region. }\end{array}$ & 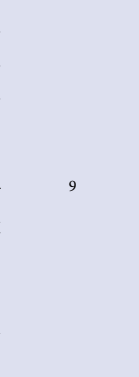 \\
\hline $\begin{array}{l}\text { in Alginate- } \\
\text { Chitosan } \\
\text { copolymer } \\
\text { microbeads. }\end{array}$ & $\begin{array}{l}\text { Extracts of six } \\
\text { different medicinal } \\
\text { herbs, nettle } \\
\text { (Urtica dioica } \\
\text { L.), hawthorn } \\
\text { (Crategus } \\
\text { laevigata), } \\
\text { raspberry leaf } \\
\text { (Rubus idaeus } \\
\text { L.), olive leaf } \\
\text { (Olea europea L.), } \\
\text { yarrow (Achillea } \\
\text { millefolium L.) } \\
\text { and (Glechoma } \\
\text { hederacea L.) }\end{array}$ & Polyphenolic & $\begin{array}{l}\text { Electrostatic } \\
\text { extrusion. }\end{array}$ & $\begin{array}{l}\text { - Raspberry leaf encapsulating microbeads exhibited the highest } \\
\text { total phenol content and antioxidant capacity, followed by } \\
\text { hawthorn, while olive leaf microbeads contained the lowest total } \\
\text { phenol content. } \\
\text { - High encapsulation efficiency was obtained for all extract } \\
\text { encapsulating microbeads ( } 80-89 \%) \text {. Nettle extract-containing } \\
\text { microparticles were character- ized with the largest particle size } \\
\text { and irregular shape, due to a high content of microelements } \\
\text { (copper, strontium, and zinc), which affected the geling process } \\
\text { of alginate. }\end{array}$ & 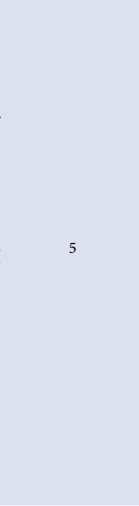 \\
\hline
\end{tabular}


$\begin{array}{cc}\text { Chitosan, } & \text { Aspalathin, a } \\ \text { maltodextrin } & \text { Rooibos extract }\end{array}$ antioxidant

$\begin{array}{cc}\text { Sodium Alginat } & \text { Quercetin } \\ \begin{array}{c}\text { Sodium caseinate } \\ \text { and Alginate }\end{array} & \text { B-karoten } \\ & \\ & \\ \text { Inulin, Sodium } & \begin{array}{c}\text { Maqui (Aristotelia } \\ \text { chilensis [Mol.] } \\ \text { Stuntz) }\end{array}\end{array}$

Alginate and $\beta$-cyclodextrin Blood Orange
Juice

Anthocyanins, Bioflavonoids, and other Polyphenols

Anthocyanins

Spray-drying

Spray drying

- Three formulations (50, 100 and $150 \mathrm{~g}$ chitosan $/ \mathrm{kg}$ powder) were compared to the pure spray- dried extract and maltodextrin containing powders (250 and $500 \mathrm{~g}$ maltodextrin/kg powder) in terms of physicochemical properties (particle size and morphology, moisture sorption isotherms, compatibility, bulk density and compressibility) and aspalathin stability during accelerated storage.

- All the formulations produced amorphous, hygroscopic powders with deliquescence at relative humidity $(\mathrm{RH})>65 \%$. The moisture content of the powders was lower than their monolayer moisture content calculated using the Brunauer-Emmet-Teller (BET) and Guggenheim- Anderson-de Boer (GAB) models. Isothermal microcalorimetry showed no interaction between extract and carbohydrate polymers. Aspalathin degradation in the powders, subjected to accelerated stability testing $\left(40^{\circ} \mathrm{C} / 75 \% \mathrm{RH}\right.$ for $\left.96 \mathrm{~h}\right)$, followed fractional conversion kinetics.

- The presence of chitosan in the powders decreased the stability of aspalathin during storage compared to the pure extract and maltodextrin-containing powders.

- Aggregates of polymer and precipitated quercetin are found homogeneously distributed within the particle matrix, that may be helpful to increase the drug load. In addition, the details of the particle surface (cracks, holes and other imperfections) appear to govern the non-homogeneous swollen and erosion.

- These findings provide complementary evidence on alginate microparticle structure to be considered when the design of this kind of carriers is intended.

- The $\beta$-carotene-loaded microparticles had a particle size $(1.87 \pm$ $0.03 \mu \mathrm{m})$ larger than that of caseinate emulsions $(0.48 \pm 0.01 \mu \mathrm{m})$ $(\mathrm{P}<.05)$.

- Microparticles were stable to aggregation over a wide $\mathrm{pH}$ range $(3-7)$ and at high salt levels $(0-1000 \mathrm{mM} \mathrm{NaCl})$, and protected $\beta$-carotene from degradation during storage.

- An in vitro digestion experiment showed that the $\beta$-carotene in microparticles had a higher bioaccessibility and chemical stability $(67.57 \pm 2.72 \%$ and $80.03 \pm 1.95 \%$, respectively) than in emulsions $(30.03 \pm 1.87 \%$ and $70.87 \pm 1.52 \%$, respectively $)(\mathrm{P}<.05)$

- The encapsulation technology using either Inulin or Sodium Alginat can be used as a protection strategy for Maqui Juice (MJ) anthocyanins by producing stable anthocyanin-rich microparticles.

- Moreover, both Encapsulating Agent improves the Bioaccessibility by $10 \%$ comparing to $\mathrm{MJ}$. The use of $\mathrm{MJ}$ as a raw material offers an additional protection effect for anthocyanins while following a more sustainable process.

- The spray-dried applied conditions were able to obtain a concentrate dried extract without the loss of Antioxidant Activity and with Total Polyphenol Content and Total Monomeric Anthocyanin values of $35-40 \%$ higher than that of the starting material. They were also effective in producing microparticles with $80-100 \%$ of encapsulation efficiency.

- The $2 \%$ sodium alginate was capable of improving the extract shelf life, while the beta-cyclodextrin (1:1 molar ratio with dried extract) prolonged the extract antioxidant efficiency by 6 hours.

- Alginate aerogels derived from $1 \mathrm{wt} \%$ solution led to a higher Gallic Acid loading and, therefore, this formulationwas used to impregnate Passion Fruit Baggase Extract (PFBE). The loading of PFBE, total phenolic, and piceatannol contents based on grams
Alginate aerogel Passion fruit microparticles bagasse extract
Polyphenols, including Emulsionpiceatannol.
Gelation method of raw aerogel were $0.62 \mathrm{~g}, 10.77 \mathrm{mg}$, and $741.85 \mu \mathrm{g}$, respectively, which means a loading efficiency of total phenolics and piceatannol of $47.1 \%$ and $34.7 \%$.

- DSC analysis and X-ray diffraction showed that particles behave as amorphous materials and ORAC assay revealed that impregnated aerogel microparticles presented antioxidant capacity.

- The AE (Antidesma puncticulatum Miq.) microparticles were successfully prepared in maltodextrin by the spray-drying method. The optimal processing conditions providing high microparticle yield and encapsulation efficiency of anthocyanins, with a low moisture content, could be achieved using the CCD.

- All tested variables significantly influenced the production yield, moisture, and encapsulation efficiency of anthocyanin content of the resultant microparticles.

$\begin{array}{cl}\text { Extract } & \text { moisture content, could be achieved using the CCD. } \\ & - \text { All tested variables significantly influenced the production yield, } \\ & \text { moisture, and encapsulation efficiency of anthocyanin content of } \\ & \text { the resultant microparticles. }\end{array}$




\begin{tabular}{|c|c|c|c|c|c|}
\hline Maltodextrin & $\begin{array}{l}\text { Hydroalcoholic } \\
\text { extracts of two } \\
\text { mushrooms } \\
\text { species, Suillus } \\
\text { luteus (L.: } \\
\text { Fries) (Sl) and } \\
\text { Coprinopsis } \\
\text { atramentaria } \\
\quad \text { (Bull.) }\end{array}$ & $\begin{array}{l}\text { Resulting in species } \\
\text { such as glu- tathione } \\
\text { (GSH), a-tocopherol } \\
\text { (vitamin E), ascorbic } \\
\text { acid (vitamin C) and } \\
\text { lipoic acid }\end{array}$ & Spray-drying & $\begin{array}{l}\text { - The spray-drying of the extracts using an extract/maltodextrin } \\
\text { ratio of } 1 / 20 \text { and an inlet temperature of } 170{ }^{\circ} \mathrm{C} \text { resulted in good } \\
\text { encapsulation yield (around } 50 \% \text { ) and effi- ciency (43.5-62.6\%.). } \\
\text { - The microencapsulated extracts with maltodextrin did not lose } \\
\text { antioxidant activity, and the combination Suillus luteus (L.: Fries) } \\
\text { (Sl) and Coprinopsis atramentaria (Bull.) (Ca) (1:1) was shown to } \\
\text { be the best as it revealed synergistic effects. The microspheres with } \\
\text { Sl:Ca (1:1) and with the free extract (in the same proportion) were } \\
\text { incorporated into cottage cheese. } \\
\text { - The results showed that, in com parison with the free form, the } \\
\text { encapsulated extracts became more effective since the antioxidant } \\
\text { activity was preserved over time. }\end{array}$ & 17 \\
\hline $\begin{array}{l}\text { Gum Arabic, } \\
\text { Maltodextrin }\end{array}$ & $\begin{array}{c}\text { Acerola } \\
\text { (Malpighia } \\
\text { emarginata DC.) }\end{array}$ & $\begin{array}{c}\text { Antioxidant } \\
\text { compounds, such as } \\
\text { ascorbic acid (AA), } \\
\text { carotenoids (CA) and } \\
\text { phenolic. }\end{array}$ & $\begin{array}{c}\text { Spray and freeze- } \\
\text { drying }\end{array}$ & $\begin{array}{l}\text { - Phenolic compounds showed significan and positive correlations } \\
\text { with all antioxidant assays. The microencapsulation efficiency was } \\
\text { greater than } 50 \% \text { for phenolic compounds and total flavonoids; in } \\
\text { addition, high antioxidant activities were also observed. } \\
\text { - In general, spray and freeze-dried powders have better } \\
\text { physicochemical characteristics. The spray-dried treatment } \\
\text { presented the best profile due to the retention of higher } \\
\text { concentrations of bioactive compounds (except ascorbic acid), } \\
\text { and antioxidant activity by FRAP and ORAC assays, supported by } \\
\text { low moisture content, aw, hygroscopicity, particle size and higher } \\
\text { solubility. }\end{array}$ & 18 \\
\hline $\begin{array}{l}\text { Gum Arabic and } \\
\text { Maltodextrins }\end{array}$ & $\begin{array}{c}\text { Jussara (Euterpe } \\
\text { edulis Martius) } \\
\text { extract }\end{array}$ & Anthocyanins & Spray drying & $\begin{array}{l}\text { - Microparticles showed high anthocyanin retention, above } 88 \% \text {. } \\
\text { Anthocyanin profiles were similar to the microparticles and } \\
\text { jussara extract and two anthocyanins identified were cyanidin } \\
\text { 3-rutinoside and cyanidin 3-glucoside. } \\
\text { - The maltodextrin } 30 \mathrm{DE} \text { provided the formation of powders of } \\
\text { higher moisture content, more hygroscopic and with a lower glass } \\
\text { transition temperature. The blend ofmaltodextrin } 10 \mathrm{DE} \text { and gum } \\
\text { Arabic (50:50 and } 75: 25 \text { ) can be selected as a good alternative as } \\
\text { carrier agents for jussara extract. }\end{array}$ & 19 \\
\hline $\begin{array}{l}\text { Maltodextrin, } \\
\text { Gum Arabic }\end{array}$ & $\begin{array}{c}\text { Rhodomyrtus } \\
\text { tomentosa (Ait.) } \\
\text { Hassk. }\end{array}$ & Flavonoids & Spray Drying & $\begin{array}{l}\text { - The optimized condition for microencapsulation was of } \\
\text { maltodextrin to gum Arabic ratio } 1: 1.3 \text {, total solid content } 27.4 \% \text {, } \\
\text { glycerol monostearate content } 0.25 \% \text {, and core to coatingmaterial } \\
\text { ratio } 3: 7 \text {, resulting inEE } 91.75 \% \text {. } \\
\text { - Prepared at the optimized condition, the flavonoids extract } \\
\text { microcapsules (FEMs)were irregularly spherical particles with } \\
\text { lowmoisture content }(3.27 \%) \text {, high solubility }(92.35 \%) \text {, and high } \\
\text { bulk density }(0.346 \mathrm{~g} / \mathrm{cm} 3) \text {. } \\
\text { - DPPH radical scavenging activity ofFEMs was not decreased after } \\
\text { spray drying }(P>0.05) \text { and higher than those in citric acid and } \\
\text { rutin at the same concentration. }\end{array}$ & 20 \\
\hline $\begin{array}{l}\text { Maltodextrin and } \\
\text { Gum Arabic }\end{array}$ & $\begin{array}{c}\text { Extract of } \\
\text { Baccharis } \\
\text { dracunculifolia }\end{array}$ & $\begin{array}{l}\text { Phenolic compounds: } \\
\text { caffeic acid, p-coumaric } \\
\text { acid, and catechin. }\end{array}$ & Spray-drying & $\begin{array}{l}\text { - Microparticles containing }(1 \rightarrow 6)-\beta \text {-d-glucan (lasiodiplodan) and } \\
\text { B. dracunculifolia extract associated with maltodextrin and gum } \\
\text { arabic was studied as a matrix material. Microparticles of } 0.4 \mu \mathrm{m} \\
\text { mean size and high phenolics content }(3157.9 \mu \mathrm{g} \text { GAE/g) were } \\
\text { obtained under the optimized conditions. The microparticle size } \\
\text { ranged from } 0.23 \text { to } 1.21 \mu \mathrm{m} \text {. } \\
\text { - Thermal analysis indicated that the microparticles demonstrated } \\
\text { high thermal stability. }\end{array}$ & 21 \\
\hline $\begin{array}{l}\text { Maltodextrin and } \\
\text { Gum Arabic }\end{array}$ & $\begin{array}{l}\text { Guarana (Paullinia } \\
\text { cupana Kunth, } \\
\text { Sapindaceae) } \\
\text { Extract }\end{array}$ & Polyphenols & Spray-drying & $\begin{array}{l}\text { - The spray-drying technique and the processing conditions selected } \\
\text { gave satisfactory encapsulation efficiency }(80-110 \%) \text { and product } \\
\text { yield }(55-60 \%) \text {. The mean diameter of microparticles was around } \\
4.5 \mu \mathrm{m} \text {. } \\
\text {-The DPPH radical scavenging capacity demonstrated that } \\
\text { microparticles can protect the semipurified extract of guarana } \\
\text { from the effect of high temperatures during the process maintained } \\
\text { the antioxidant capacity. } \\
\text { - In vitro dissolution tests demonstrate that all formulations } \\
\text { complete dissolution within } 60 \text { min. Microencapsula- tion } \\
\text { improved the technological characteristics of the powders and } \\
\text { preserved the antioxidant properties. }\end{array}$ & 22 \\
\hline $\begin{array}{l}\text { Maltodextrin } \\
(\mathrm{MD}) \text {, colloidal } \\
\text { silicon dioxide } \\
(\mathrm{A}) \text {, arabic } \\
\text { gum }(\mathrm{E}) \text { and } \beta \text { - } \\
\text { cyclodextrin ( } \beta \\
\quad-\mathrm{CD})\end{array}$ & Psidium guajava L. & $\begin{array}{l}\text { Alkaloids, tannins, } \\
\text { flavonoids and phenolic } \\
\text { compounds. }\end{array}$ & Spray drying & $\begin{array}{l}\text { - The results of the present study showed that the spray dried guava } \\
\text { leaves extracts present potential antioxidant and antimicrobial } \\
\text { activities. Psidium guajava leaves extract showed antibacterial } \\
\text { activity against S. aureus and also showed antifungal activity } \\
\text { against C. glabrata. } \\
\text { - The spray dried guava leaves extracts exhibited stronger } \\
\text { antimicrobial activity against S. aureus and C. glabrata, evidenc- } \\
\text { ing their potential as a natural antimicrobial agent for medicinal, } \\
\text { cosmeceutical and food purposes }\end{array}$ & 23 \\
\hline
\end{tabular}


Maltodextrin

(MD), gum Arabic (GA), and whey proteins (WP)

$\begin{array}{cc} & \text { Extracts } \\ & \text { from Fadogia } \\ \text { Maltodextrin/ } & \text { ancylantha, } \\ \text { apple- pectin } & \text { Melissa officinalis } \\ \text { and Tussilago } \\ \text { farfara }\end{array}$

Polyphenol (flavonoids and cynnamicacid derivatives)

farfara

k-carrageenan and Morinda citrifolia maltodextrin L. extract

Phenolic and flavonoid

extract of

Gum arabic and xanthan gums schweilera nana Miers leaves
Flavonoids, such as rutin and hyperoside
Spray-drying

Spray chilling

\section{Unripe banana starch films} ratios $(70 / 30$ and 80/20 g:g) as carriers (SLM).

PVP and colloidal silicon dioxide

Inulin

(HE/rapeseed oil/pectin) and a cross-linked solution $\left(\mathrm{CaCl}_{2}\right)$

Gelucire 50/13

(Stearoyl

polyoxyl-32

glycerides)
Curcuma longa L. Curcumin

Polyphenols

Spray-drying

Hibiscus

sabdariffa L

extract

Wild garlic (A.

ursinum) extract

Spray drying
Spray-drying

- The Whey Proteins based samples had the highest powder yield and smallest particles using scanning electron microscopy. Maltodextrin led to higher solubility, hygroscopicity, color stability, and anti- $\alpha$-glucosidase activity.

-The combined wall-materials, especially, Whey Proteins with Gum Aarabic or Maltodextrin, increased the polyphenols stability and their antioxidant capacity during storage better than their individual counterparts.

- A maltodextrin/pectin (M/P) matrix was studied for its ability to carry sensitive polyphenol-rich extracts via spray-drying.

- The use of a 10:1 M/P weight ratio $(11 \% \mathrm{w} / \mathrm{v})$ led to encapsulate $3 \% \mathrm{w} / \mathrm{v}$ polyphenol-rich extracts forming stable powders made up of well-formed and micronized particles suitable for storage and handling.

- The results showed that the percentage of 2,2-diphenyl picrylhydrazyl (DPPH) scavenging activity of the spray-dried powder was the highest for the 1:2 ratio (volume ratio of $\mathrm{M}$. citrifolia L. extract to additive solution) at $90 \otimes \mathrm{C}$, with maltodextrin at a concentration of $33 \mathrm{mg} / \mathrm{ml}$.

- The results also showed that the microcapsules had a regular spherical shape. The spray-dried M. citrifolia fruit extract showed high antioxidant activity (28.36\% DPPH activity), thus suggesting that it might be useful as a food additive and/or ingredient under the above optimum operating conditions.

- Results showed that, using the spray-drying technique, it was possible to obtain microparticulate systems containing E. nana extract with high encapsulation efficiency of rutin and hyperoside, which may be associated to a possible interaction between the polymers and the extract.

- All microparticle formulations were amorphous, hollow, and spherical with smooth surfaces. Thermal analysis revealed that the microencapsulation process conferred thermal protection to the extract. The release profile of rutin was carried out and showed that from the microparticles it was slower than the extract.

- The film produced with microparticles containing a lauric acid/ oleic acid ratio of $80 / 20$ (g:g) as carrier and a carrier/core ratio of $75 / 25$ (g:g) presented the lowest water vapor permeability and retained the highest antioxidant activity (84\%) during film processing.

- The microparticles were spherical in shape, and an increase in outlet temperature from 40 to $80{ }^{\circ} \mathrm{C}$ resulted in a significant increase in the yield of microparticles from 16 to $53 \%$.

- The total curcuminoid content ( 17.15 to $19.57 \mathrm{mg} / \mathrm{g}$ ), curcumin content (3.24 to $4.25 \mathrm{mg} / \mathrm{g}$ ) and antioxidant activity (530.1 to 860.3 $\mu \mathrm{g} / \mathrm{mL}$ ) were also affected by the spray drying process.

- The solubility of curcuminoid from C. longa remarkably improved 100 -fold in the microparticles.

- Olive leaves extract (OLE) was microencapsulated with inulin (OLE-IN) by spray-drying using a central composite design. Oleuropein encapsulation efficiency and recovery values were over $87 \%$ in the OLE-IN microparticles obtained under optimal conditions.

- Microencapsulation of hibiscus anthocyanin resulted in improved enteric protection of bioactive compound, mainly in microparticles generated by dripping-extrusion. Application in jelly candy has shown to be technically feasible, with retention of up to $73 \%$ of bioactive compounds and mean sensorial acceptance of $70 \%$ tasters.

- The microparticles exhibited spherical shape, mean diameter in the range 100-200 $\mu \mathrm{m}$, high encapsulation efficiency and good stability during three months of storage, with no signs of chemical or physical modifications.

Spray-congealing - Encapsulation of wild garlic extract in Gelucire 50/13 microparticles by spray congealing proved to be a successful strategy to improve solubility and dissolution rate of the extract maintaining the antimicrobial activity and providing advantageous technological properties. 
Maltodextrin/ Modified

Maize Starch

combination

\section{Echium amoenum} petal

Anthocyanins

Spray-drying

$\beta$-cyclodextrin

and chitosan

White wines

Glutathione

Spray-drying

\section{B-glucan and}

$\beta$-cyclodextrin

Saffron

Anthocyanins

Spray-drying

Pea Protein

Propolis extract

Phenolic

Spray-drying

Flavan-3-ol

Alginat-calsium caseinate,

Chitosan-pectin

Green tea extract
- The results of this study showed that the combination of maltodextrin (MD)/modified maize starch (MMS) can trap the anthocyanins extracted from IBE with high encapsulation efficiency. Among all treatments tested, the combination of MD/ MMS (1:1) led to the better protection of anthocyanin compounds.

- The FTIR spectra confirmed the formation of microcapsules, while DSC studies indicated that the thermal stability of IBE could significantly be increased. The morphology of all treatments demonstrated spherical wrinkled and non-fractured surfaces in microstructures.

- A formulation containing MD/MMS (1:1) had the best stability of anthocyanins over 60 days storage and also showed a slight reduction of antioxidant activity over the same period.

- SEM showed spherical microparticles, with wrinkled surfaces for $\beta$-CD/GSH and smooth surfaces for chitosan/GSH. A wide distribution of particle size was observed. In general, $\beta-C D /$ GSHshowed an average diameter smaller than the chitosan/GSH microparticles.

- FT-IR showed a possible interaction between GSH and both polymers. DSC and DRX showed that encapsulation process produced a marked decrease in GSH crystallinity.

- The encapsulation efficiency was $25.0 \%$ for chitosan/GSH and $62.4 \%$ for $\beta-\mathrm{CD} / \mathrm{GSH}$ microparticles. The GSH release profiles from microparticles showed that $\beta-\mathrm{CD}$ can control the release behaviors of GSH better than chitosan in a model wine.

- The findings of this study showed that $\beta$-glucan has potential to encapsulate saffron bioactives and improves its stability during passage through simulated GI tract conditions.

- Encapsulation increased the availability of anthocyanins in intestinal section, which can lead to their maximium abosrbtion during oral digestion. The presence of anthocyanins in $\beta$-glucan matrix was clearly depicted through SEM and FT-IR spectroscopy.

- The best propolis extract (PE) concentration was $5 \%(\mathrm{w} / \mathrm{v})$ and pea protein (CPP) was $2 \%(\mathrm{w} / \mathrm{v})$, presenting the highest encapsulation efficiency and yield, although all the microparticles presented lower antioxidant activity than PE.

- ATR-FTIR and X-ray diffraction techniques suggest that encapsulation occurred because they demonstrated that there was an interaction between PE and CPP, and the microparticles showed amorphous state, respectively.

- The PE showed antimicrobial activity against Gram-positive and Gram-negative bacteria. Microparticles in which $2.5 \%$ and $5 \%$ of PE and 2\% of CPP were used showed bacteriostatic and even bactericidal effect against Staphylococcus aureus and Listeria monocytogenes.

- Employing alginate in combination with soy or hemp proteins provided large and hard particles, while reinforcement with whey proteins and bovine serum albumin provided the most spherical and softer particles (lower hardness and elasticity), with average diameters around $700-800 \mu \mathrm{m}$. The combination of alginate and calcium caseinate or whey proteins enabled to retain the highest content of polyphenols and caffeine in the formulated particles (up to $80 \%$ ).

- Chitosan or pectin coating did not improve the physical and morphological properties or the encapsulation efficiency, but conferred better (prolongued) release profile of polyphenols from the particles. The release studies in water and simulated gastric and intestinal fluids revealed burst release of polyphenols (over $50 \%$ in first $5-10$ minutes) followed by sustained release up to 120 minutes. gastrointestinal tract (GIT) after ingestion, and can also be designed to control the site or rate of the bioactive release within the. Caseinate/ alginate microparticles were previously prepared by our group to encapsulate protein nanoparticles so as to protect them and control their release. ${ }^{12}$

Pectin and alginate have been widely used in food applications because of their biocompatibility, biodegradability, non-toxicity, and low cost. Pectin is a natural anionic, linear water-soluble polysaccharide whose main component is galacturonic acid, whereas alginate consists of two monomeric structures $(\beta$-D-mannuronic acid $(\mathrm{M})$ and $\alpha$-L-guluronic acid $(G)$ ). Alginate-pectin mixtures have synergistic properties that allow them to form different microstructure of each biopolymer. Some researchers have studied the combination of sodium alginate and pectin citrate when preparing microparticles containing drugs, reporting that this mixture can form strong complexes through chain associations, as well as hydrogels when multivalent cations are added to form particles with high encapsulation efficiency, release kinetics are modified and improved mechanical and chemical stability. ${ }^{38}$ 
Spray-drying is a well-established and widely used technique for transforming liquid foods or suspensions into a powder in a one-step process. The method is easy to operate, requiring only a few steps to obtain a dry product; the process is easily scaled up and does not require the use of organic solvents, i.e., its use provides a good cost-benefit. Both for food processing and for cosmetic proposes, the technique has been extensively used for the protection and controlled release of bioactive compounds, mainly antioxidants. ${ }^{26,4}$ The microencapsulation technique of spray-drying is an effective way to protect drug or food ingredients against deterioration and volatile losses. Since the instability of antioxidant has a direct impact on both colour property and bioavailability, performing microencapsulation by applying the spray drying technology and combining this technique with natural biopolymers may be an efficient way for protecting the important substances that are sensitive to adverse environmental conditions. The protective mechanism consists of the formation of a membrane wall that encloses droplets or particles of the encapsulated material. The choice of a particular method depends on the type of microparticles desired. The properties of the wall structures, size and shape are important considerations. However, in the food and drug industry, spray-drying is still the most popular method of forming microparticles because it is very easy to industrialise and allows for continuous production. Spray-drying is one of the techniques for microparticle production and it offers advantages because it involves low technical costs, is simple (performed in just one stage), versatile (it can be used for the production of microparticles, using different polymers) and, apart from easy control of its parameters, it is capable of producing microparticles of a uniform size. The spray drying process is composed of three steps: atomisation, dehydration, and microparticle collection. This method can include many antioxidant inside the encapsulated material and is easy to scale for industrial production. ${ }^{26,16,7}$

\section{Characterization of microparticles containing extract with antioxidant activity}

\section{Morphology}

Examination of the shape and surface morphology of the microcapsules Scanning Electron Microscopy (SEM) to determine the surface characteristics and the presence of pores on the surface of the microcapsules. ${ }^{9}$

\section{Particle size and $\zeta$-potential}

Characterization of particle size is important it is known whether the particle size of the microcapsules is in the optimal range. several tools that can be used to measure particle size such as Particle Size Analysis, Atomic Force Microscopy, Coulter Counter and Image Analysis. Measurement of $\zeta$-potential can provide information about the stability of colloidal dispersion systems during storage namely the possibility of aggregate formation on charged particles. ${ }^{12}$

\section{Physical properties}

The physical characterization of microparticles includes moisture content, density, porosity, flowability, compressibility, swelling and wetting. ${ }^{4,710}$

\section{Drug load and Encapsulation Efficiency}

The success of drug loading can be expressed by actual loading and entrapment efficiency (encapsulation). Determination of the microcapsule drug content was carried out to determine the amount of active substance which can be encapsulated and the efficiency of the method used. The method used depends on the solubility of the coating material and the core material, one of the methods is spectrophotometry

UV-Vis. :
$\%$ Yield of the process $(R)$

The quantity of microparticles obtained at the end of the process $(Q f)$ $=\frac{T \text { he amount of solids added for the preparation of microparticles }(Q i)}{T} \times 100 \%$

\% Encapsulation Efficiency

Fraction of active substances in microparticles (Qobtained) $=\frac{\text { Theorical fraction of active substances in microparticles }(Q \text { theorical })}{100 \%}$

Microcapsules can contain up to $100 \%$ core material calculated against the weight of the microcapsules. The ideal entrapment efficiency is influenced by various factors such as the type and state of the process. ${ }^{4}$

\section{Antioxidant activity}

The evaluation of antioxidant activity in vitro microencapsulation was carried out through DPPH evaluation capturing free radicals and ABTS. To prepare the sample, the microparticles are subjected to the same procedure used to determine the efficiency of encapsulation. ${ }^{5}$

\section{Drug release}

In vitro release tests were carried out to measure the rate and amount dissolving drugs in a medium in the presence of one or more additives contained in the active substance. The release process begins with the dissolution of material on the surface of the particles of the active substance, which forms a clear solution around the particles. Drugs that are dissolved in clear solution are assumed to be stagnant layers which subsequently diffuse from high to low concentrations. ${ }^{10}$

\section{Stability}

The selected microparticles were submitted to the stability study considering the active substances content during storage at different temperatures. Samples of the selected microparticles were stored under the following conditions: refrigerated temperature (ReT) 2 to $6{ }^{\circ} \mathrm{C}$; room temperature (RoT) $25^{\circ} \mathrm{C}$; and stress temperature (StT) $40^{\circ} \mathrm{C} .4^{4}$

\section{Other Studies}

The possible interaction between the polymer and the drug was investigated by using differential scanning calorimetry (DSC) and Fourier-transform infrared spectroscopy (FT-IR). The Thermogravimetric (TG) method and differential scanning calorimetry (DSC) provide valuable data on the polymer thermal compatibility. Measured glass transition temperatures play an important role in the production and release as well. The Spectrometry Method with FourierTransform Infrared (FT-IR) Analysis can be performed to follow intramolecular changes during microencapsulation. ${ }^{11,10}$

\section{REFERENCES}

1. Neha, K., Haider, R., Pathak, A. \& Yar, M. S. European Journal of Medicinal Chemistry Medicinal prospects of antioxidants : A review. 178. 2019.

2. Ozkan, G., Franco, P., Marco, I. De, Xiao, J. \& Capanoglu, E. A review of microencapsulation methods for food antioxidants: Principles, advantages, drawbacks and applications. Food Chem. 272. 2019;494-506.

3. Tarone, A. G., Baú, C., Cazarin, B. \& Roberto, M. Anthocyanins: New techniques and challenges in microencapsulation. Food Res. Int. 109092. 2020.

4. Cabral, B. et al. Improving stability of antioxidant compounds from Plinia cauliflora (jabuticaba) fruit peel extract by encapsulation in chitosan microparticles. J. Food Eng. 2018.

5. Bel, A. et al. Encapsulation of polyphenolic antioxidants from medicinal plant extracts in alginate-chitosan system enhanced with ascorbic acid by electrostatic extrusion. 44. 2011;1094-1101.

6. Li, Y. O., Gonza, D. \& Diosady, L. L. Microencapsulation of Vitamins, Minerals and Nutraceuticals for Food Applications. 2013;501-522.

7. Garrastazu, G., Britto, C., Lima, T., Raf, A. \& Stanisçuaski, S. Journal of Drug Delivery Science and Technology a-tocopherol acetate-loaded chitosan microparticles: Stability during spray drying process, photostability and swelling evaluation. 30. 2015;220-224.

8. Barbosa, Q., Lourenc, R. V. \& Jos, P. Properties of gelatin-based films incorporated with chitosan-coated microparticles charged with rutin. Int. J. Biol. Macromol. 2017. 
9. Endo, H. E., Ueda-Nakamura, T., Nakamura, C. V. \& Filho, B. P. D. F. Activity of Spray-dried Microparticles Containing Pomegranate Peel Extract against Candida albicans. Molecules 17. 2012;10094-10107.

10. Human, C. et al. LWT - Food Science and Technology Preparation of rooibos extract-chitosan microparticles: Physicochemical characterisation and stability of aspalathin during accelerated storage. LWT - Food Sci. Technol. 117. 2020;108653.

11. Cadena-velandia, Z. G., Montenegro-alarcón, J. C. \& Mora-huertas, C. E. Quercetin-loaded alginate microparticles: A contribution on the particle structure. J. Drug Deliv. Sci. Technol. 2020;101558.

12. Liu, W., Wang, J., Julian, D. \& Zou, L. Encapsulation of $\beta$-carotene-loaded oil droplets in caseinate / alginate microparticles: Enhancement of carotenoid stability and bioaccessibility. J. Funct. Foods 40. 2018;527-535.

13. Fredes, C., Osorio, M. J., Parada, J. \& Robert, P. Stability and bioaccessibility of anthocyanins from maqui (Aristotelia chilensis [Mol.] Stuntz) juice microparticles. LWT - Food Sci. Technol. 2018.

14. Lauro, M. R. et al. An Alginate / Cyclodextrin Spray Drying Matrix to Improve Shelf Life and Antioxidant Efficiency of a Blood Orange By-Product Extract Rich in Polyphenols: MMPs Inhibition and Antiglycation Activity in Dysmetabolic Diseases. Hindawi. 2017.

15. Viganó, J. et al. International Journal of Biological Macromolecules Impregnation of passion fruit bagasse extract in alginate aerogel microparticles. Int. J. Biol. Macromol. 2019

16. Yingngam, B., Tantiraksaroj, K. \& Taweetao, T. Modelling and Stability Study of the Anthocyanin-Rich Maoberry Fruit Extract in the Fast-Dissolving Spray-Dried Microparticles. Powder Technol. 2017.

17. Ribeiro, A. et al. Spray-drying microencapsulation of synergistic antioxidant mushroom extracts and their use as functional food ingredients. FOOD Chem. 188. $2015 ; 612-618$

18. Rafaella, Y., Santos, R., Nogueira, J. P. \& Narain, N. Microencapsulation of extracts of bioactive compounds obtained from acerola (Malpighia emarginata DC) pulp and residue by spray and freeze drying : Chemical, morphological and chemometric characterization. Food Chem. 254. 2018;281-291.

19. Gabriela, A. et al. Physical properties and morphology of spray dried microparticles containing anthocyanins of jussara (Euterpe edulis Martius) extract. Powder Technol. 294. 2016;421-428.

20. Wu, P. et al. Spray Drying of Rhodomyrtus tomentosa ( Ait .) Hassk . Flavonoids Extract: Optimization and Physicochemical, Morphological, and Antioxidant Properties. Hindawi. 2014.

21. Iurckevicz, G. et al. Encapsulated Microparticles of ( $1 \rightarrow 6)-\beta$-d-Glucan Containing Extract of Baccharis dracunculifolia : Production and Characterization. Moleculs 24, 2099. 2019 .

22. Klein, T., Longhini, R., Bruschi, M. L. \& Mello, J. C. P. De. Microparticles containing guarana extract obtained by spray drying technique: development and characterization. Rev. Bras. Farmacogn. 25. 2015;292-300.

23. Fernandes, M. R. V, Dias, A. L. T., Carvalho, R. R., Souza, C. R. F. \& Oliveira, W. P. Antioxidant and antimicrobial activities of Psidium guajava $L$. spray dried extracts. Ind. Crop. Prod. 60. 2014;39-44.
24. Khalifa, I., Li, M., Mamet, T. \& Li, C. Food Bioscience Maltodextrin or gum Arabic with whey proteins as wall-material blends increased the stability and physiochemical characteristics of mulberry microparticles. Food Biosci. 31 100445. 2019.

25. Sansone, F. et al. Maltodextrin / pectin microparticles by spray drying as carrier for nutraceutical extracts. J. Food Eng. 105. 2011;468-476.

26. Krishnaiah, D., Sarbatly, R. \& Nithyanandam, R. Chemical Engineering Research and Design Microencapsulation of Morinda citrifolia $L$. extract by spray-drying Chem. Eng. Res. Des. 90. 2011;622-632.

27. Outuki, P. M. et al. Development of arabic and xanthan gum microparticles loaded with an extract of Eschweilera nana Miers leaves with antioxidant capacity. Colloids Surfaces A Physicochem. Eng. Asp. 2016.

28. Sartori, T. \& Menegalli, F. C. Food Hydrocolloids Development and characterization of unripe banana starch fi Ims incorporated with solid lipid microparticles containing ascorbic acid. Food Hydrocoll. 55. 2016;210-219.

29. Martins, R. M. et al. Curcuminoid content and antioxidant activity in spray dried microparticles containing turmeric extract. FRIN 50, 2013;657-663.

30. Urzua Catalina, Gonzales Estefania, Dueik Veronica, Bouchon Pedro, Gimenez Begona, R. P. Olive leaves extract encapsulated by spray-drying in vacuum fried starch - gluten doughs. Food Bioprod. Process. 6. 2017;171-180.

31. Moura, S. C. S. R. De et al. Release of anthocyanins from the hibiscus extract encapsulated by ionic gelation and application of microparticles in jelly candy. Food Res. Int. 121. 2019;542-552.

32. Tom, A., Bertoni, S., Protti, M. \& Albertini, B. Encapsulations of wild garlic (Allium ursinum $L$.) extract using spray congealing technology Food Research International Encapsulations of wild garlic (Allium ursinum L.) extract using spray congealing technology. 2019.

33. Mehran, M., Masoum, S. \& Memarzadeh, M. Preparation and characterization of microparticles of $\beta$-cyclodextrin/glutathione and chitosan/glutathione obtained by spray-drying. Int. J. Biol. Macromol. 2020.

34. Webber, V., Ferreira, D. D. S., Manique, P. L., Angeli, V. W. \& Vanderlinde, R. Improvement of thermal stability and antioxidant activity of anthocyanins of Echium amoenum petal using maltodextrin/modified starch combination as wall material. Food Res. Int. 2017.

35. Ahmad, M., Ashraf, B., Gani, A. \& Gani, A. Microencapsulation of saffron anthocyanins using $\beta$ glucan and $\beta$ cyclodextrin : Nutraceutical, morphological, structural and the release behavior of capsules during in-vitro digestion. Int. J. Biol. Macromol. 2017.

36. Jansen-alves, C. et al. Propolis microparticles produced with pea protein Characterization and evaluation of antioxidant and antimicrobial activities. Food Hydrocoll. 2018.

37. Belscak-cvitanovic, A., Dordevic, V., Karlovic, S. \& Pavlovic, V. Protein-reinforced and chitosan-pectin coated alginate microparticles for delivery of flavan-3-ol antioxidants and caffeine from green tea extract. Food Hydrocoll. 2015.

38. Real, A. Del. Spray-drying method for the encapsulation of a functionalized ingredient in alginate-pectin nano-and microparticles loaded with distinct natural actives: Stability and antioxidant effect. Food Hydrocoll. 105560. 2019. 


\section{GRAPHICAL ABSTRACT}

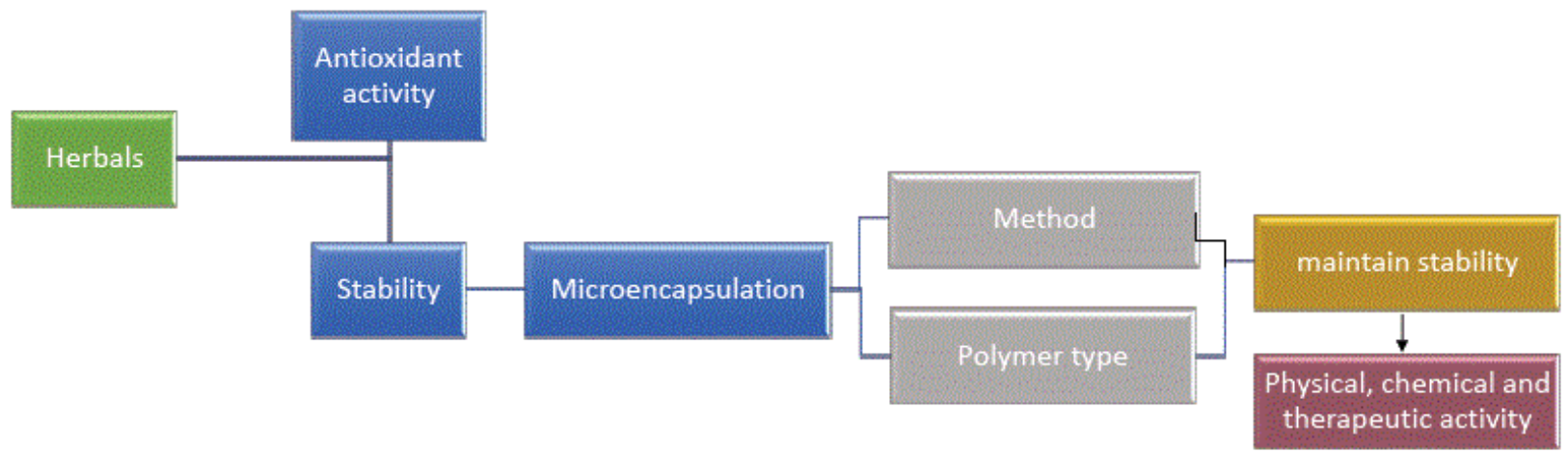

\section{ABOUT AUTHORS}

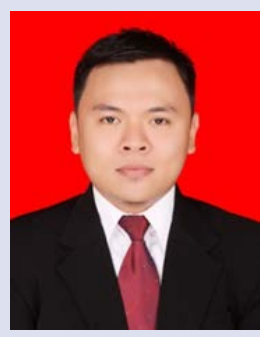

Zulham is a Lecturer and Researcher at the Department of Pharmaceutics, Sekolah Tinggi IImu Farmasi, Makassar, Indonesia. He has an interest in the field of pharmaceutical technology towards the development of natural products. He has written several publications on the results of his research on natural products in several journals. Currently, he is conducting dissertation research on the microencapsulation of kesambi leaf extract (Schleichera oleosa L.) on solid dosage form as a hepatoprotector candidate.

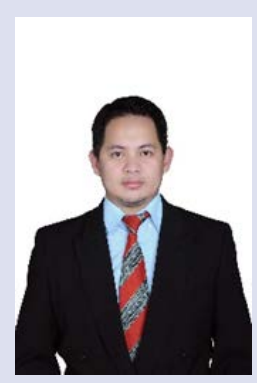

Gofarana Wilar is a lecturer in department of pharmacology and clinical pharmacy, faculty of pharmacy Universitas Padjadjaran since 2008. He took undergraduate and Pharmacist licence Program at Faculty of Pharmacy Universitas Padjadjaran, Indonesia. He took the master degree from school of Pharmacy Institute Technology Bandung, Indonesia. He finished his doctoral study in graduate school of Pharmaceutical Sciences, School of Pharmacy, Tohoku Universiaty, Japan. His research has been focused on the pharmacological activity of natural product and neurochemical mechanism of addiction such as nicotine dependence .

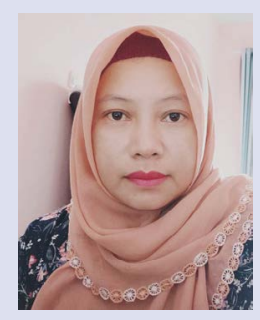

Yasmiwar Susilawati: Associate Professor at Department of Pharmaceutical Biology, Faculty of Pharmacy, Padjadjaran University, Jatinangor, Indonesia. She has been working on many research in the area of Pharmacognosy, phytochesmistry and etnopharmacognosy. Her dissertation was about finding new antidiabetic compounds from herb Peperomia pellucida. Many researches on pharmaceutical active compound has been her current interest. Some of her project has been developed into many pharmaceutical dosage forms and this has been her focus of interest during the last few years.

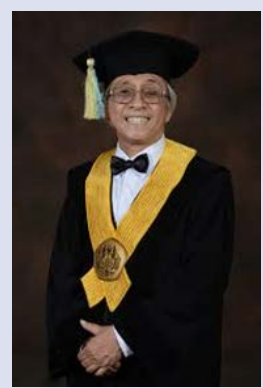

Anas Subarnas is a Professor at Department of Pharmacology and clinical pharmacy, Faculty of Pharmacy, Padjadjaran University, Jatinangor, Indonesia. He finished his magister in Natural product from Pharmaceutical Institute, Tohoku University, Sendai, Japan and finished his doctoral programme in the field of pharmacology from Pharmaceutical Institute, Tohoku University, Sendai, Japan. He conducted his Postdoctoral research in Institut fur Pharmazeutische Biologie, Universitat Munchen Germany and also in Department of Pharmaceutical Biology, Institute of Pharmacy, Ludwig-Maximilians University, Munchen, Germany. He has been working the research in many area of biochemical activities including antihyperurisemia of akar pakis tangkur (Polypodium feel) extract, Apoptosis induced in MCF-7 human breast cancer cells isolated from Eugenia aquea Burm $f$. Leaves and many more. He wrote many publications and reviews in journal as well as books. 


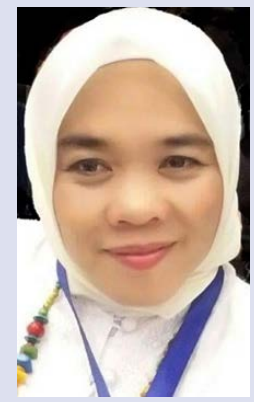

Anis Yohana Chaerunisaa: Associate Professor at Department of Pharmaceutics and Pharmaceutical Technology, Faculty of Pharmacy, Padjadjaran University, Jatinangor, Indonesia. She currently work on many research in the area of Pharmaceutical Technology and drug delivery including solid, liquid and semisolid dosage forms as well as developing polymer and other excipients for pharmaceutical dosage forms. She wrote dissertation on release adjustment of drug combined in one dosage form. She also has many experiences on drug discovery from herbals either as active compound or alternative for adjuvant therapy. She wrote many publications about her research on pharmaceutical dosage forms in many journals, as well as some books and book chapter. She is also pursuing interests on development of nanoparticles from synthesis and herbal active compounds.

Cite this article: Zulham, Wilar G, Susilawati Y, Subarnas A, Chaerunisaa AY. Microparticles of Herbal Extracts with Antioxidant Activity. Pharmacog J. 2021;13(1): 285-95. 